freely as to be almost ubiquitous, occurring for example throughout the variety Up-to-Date, and in all American commercial potatoes without exception, its vector is unknown. It infiltrates rapidly into virus-free stocks even when grown in isolation in the best districts, and is not entirely unknown in experimental glasshouses. As part of the basis of all the severe mosaics it is an active danger, but the question still awaits answer whether it is economically possible or necessary to control it as well as the aphis-borne viruses.

The viruses mentioned are not uniformly distributed throughout Great Britain and Ireland. In the best districts, leaf roll is absent, $Y$ is rare, $A$ is more common and $X$ is nearly universal, while in the south-east leaf roll and virus $Y$ become comparatively common. The useful life of a variety depends on its reaction to the local viruses, and the moderate reactors suffer most and last shortest, a good example being Arran Chief. The carriers and strong reactors escape best. Outstanding varieties, such as the famous Up-to-Date and British Queen, are intolerant of $A$ and probably resist infection with it as well. Up-to-Date tolerates $X$ and British Queen resists it. It appears to be the reaction to these two viruses which determines the survival of a variety in Great Britain. If it tolerates $Y$ as well so much the better, but our best potatoes lack this quality, a fact which explains the failure of Up-to-Date in the interior of the United States and Canada, as probably also in Central Europe. The control of virus $Y$ at home depends on the use of Scottish and Irish seed potatoes.

\title{
Dental Caries and Diet
}

$\mathrm{I}^{\mathrm{N}}$ spite of the facts that there are more dental clinics, that many more people brush their teeth and that more dental treatment is practised to-day than ever in the world before, dental disease seems to be as prevalent as it has ever been, especially among civilized peoples. The experimental work of Mrs. Mellanby has shown that there is an intimate relationship between the diet and the structure of the teeth in both animals and man, and that there is similarly a close relationship between structure and liability to caries in man. It remained to be proved that the incidence and progress of the disease could be influenced by alterations or additions to the diet.

The results obtained in the first stages of the investigations carried out with this object have already been referred to in these columns (NATURE, 129, 83; 1932 : 133, 820; 1934). The final report* of the Committee for the Investigation of Dental Disease describes the influence of diet upon caries in children's teeth and shows that the teeth, like other organs of the body, are strongly influenced by nutritional factors brought to bear upon them, whether through their blood supply or the saliva. The dental decay that developed in the children receiving an addition of vitamin $\mathrm{D}$ to their diet was definitely less than in the control children not receiving extra vitamin, and its influence in inhibiting the initiation and spread of caries was especially impressive when the addition was made during the period of development and before full eruption of the teeth.

* Medical Research Council. Special Report Series, No. 211 : The Influence of Diet on Caries in Children's Teeth (Final Report). By the Committee for the Investigation of Dental Disease (assisted by Alan Deverall and Mabel Reynolds). Pp. ii +137 . (London: H.M. Stationery Office, 1936.) 28. net.
The investigations were made in three similar institutions in the neighbourhood of Birmingham, maintained on the Cottage Home System, under the Poor Law authority and later under the local education authority. It was at first hoped to divide the children in each institution into three groups, each receiving a different supplement, so as to avoid the possible influence of slightly differing conditions in the homes affecting the results, but administrative difficulties prevented this and all the children in one home were given the same addition. Analysis of the basal diets showed that they were fairly similar in the three institutions : the variations, described in the report, probably did not affect the general conclusions drawn from the results obtained. Three experiments were carried out. In the first, the three institutions had daily additions to the diet of treacle (2842 gm.), olive oil (14-21 c.c.) and cod liver oil (14-21 c.c.; 50-100 units of vitamin D per c.c.) respectively. In the second, carried out in one institution only, one group of children received the olive oil and the other vitamin $\mathrm{D}$ in olive oil (625 units per c.c. : 14-21 c.c.). In the third, the children were younger ( $2-5$ years old) instead of 5-14 years old, and the additions were treacle, vitamin $\mathrm{D}$ in olive oil and cod liver oil in daily doses of $7 \mathrm{gm}$. or 7 e.c., in three different institutions. Although about 1,600 children were under observation for varying lengths of time, the number who received the special additions for the full period of three years was much less.

Six-monthly examinations were made of the mouth and of the general physical condition with 
special reference to the bones. The surface structure of the teeth, their arrangement in the jaws, the number of carious teeth and the extent of caries in each, as well as the condition of the gums and the general physical state were noted at the beginning of the investigation and at each subsequent examination. The differences between the findings at the first and final inspections in each diet group were then compared.

This investigation has shown again that there is a definite direct association between the structure of the teeth and the amount of caries present in a mouth: this relationship was found in the case of both the original and newly erupted permanent teeth in the olive oil group. Although no definite evidence was obtained that diet had an effect upon the structure of the permanent teeth, there were indications that the addition of vitamin $\mathrm{D}$ during the period of development tends to improve the structure of the first permanent molars. On the other hand, it was proved conclusively that a high vitamin $\mathrm{D}$ intake before the full eruption of the permanent teeth significantly diminishes the incidence of caries in such teeth after eruption : this protective effect was especially striking in the case of the premolars and second permanent molars, which erupt later than the first permanent molars. As regards the deciduous teeth, only in the case of the youngest children could any effect of the additions to the diet be expected; evidence was obtained that caries was less progressive in the vitamin groups than in that receiving treacle.

It is of interest to note that although the incidence of fresh caries in the permanent teeth present at the beginning of the investigation was the same in the two control groups, yet the spread and degree of softening were significantly greater in the olive oil group : in the case of the deciduous teeth, however, there was a greater increase in the percentage of carious teeth in the treacle than in the olive oil group.

Summing up the results of these extensive experiments, it may be concluded that a relatively high intake of vitamin $\mathbf{D}$ can do much to diminish the incidence of caries if the vitamin is given during the period of development of the teeth : that a beneficial effect may be obtained if it is given at a fairly late stage of development; and that even when it is given after the eruption of the teeth, the onset and spread of caries are delayed.

\section{Problems of Plantation Economy}

IN choosing the subject of "Plantation Economy" 1 for his presidential address to Section $\mathrm{F}$ (Economics and Statistical Science) of the British Association, delivered at Blackpool on September 11, Dr. C. R. Fay rightly directed attention to a neglected corner of knowledge which has lessons of much interest to the sociologist as well as the economist, to the historian, the geographer and the administrator as well as the agriculturist. Dr. Fay was clearly inspired by a recent tour in the East, and dealt mainly with the tea plantations of India. He contented himself with a straightforward account of the industry, and refrained, perhaps wisely, from comment on the wider issues.

The Royal Commission on Labour in India (1931) pointed out the similarity between a plantation and a factory--both employing a considerable number of persons under the control of a manager. The chief difference is that the work in one case is essentially agricultural and is not concentrated in a large building. The analogy is important; until regulated by factory acts, 'exploitation' of labour too often characterized the growing manufacturing industry just as exploitation of labour-including slavery-characterized the early plantation industry. Tobacco in the south-eastern United States, and sugar in the West Indies a hundred or more years ago, ought to be thought of in comparison with the Lancashire cotton mills of the same period. It is scarcely possible to contemplate the modern world without a factory system, yet the corresponding plantation system is not only less important than formerly, but also may be described as 'suspect'. To-day, India, Further India and the East Indies are the home of the greatest plantation industries, tea and rubber, and this is considered by Dr. Fay to be due in considerable measure to Government opposition to the system in Africa. Dr. Fay quotes figures in his opening paragraph to show that, despite a relatively small area, plantation products (mainly tea) account for nearly a fifth by value of the agricultural exports of India. This statement has little meaning-what one would like to know is the relative productivity of a given area of land under plantation organization and under unregulated native cultivation, and the relative cost per unit of production, having due regard to quality. 